\title{
Wildfire risk to water supply catchments: A Monte Carlo simulation model
}

\author{
$\underline{\text { C. Mason }}{ }^{\text {a }}$, G. Sheridan ${ }^{\text {a }}$, H. Smith ${ }^{\text {b }}$, D. Chong ${ }^{\text {a }}$ and K. Tolhurst ${ }^{\text {a }}$ \\ ${ }^{a}$ Department of Forest and Ecosystem Science, The University of Melbourne ${ }^{b}$ School of Geography, Earth and \\ Environmental Sciences, University of Plymouth \\ Email: cimason@student.unimelb.edu.au
}

\begin{abstract}
Wildfires create burnt areas which may be vulnerable to increased erosion when affected by high intensity or long duration storm rainfall. This vulnerability is most apparent in the first year after fire and reduces as soil and vegetation recover. Post-fire erosion events may deliver large quantities of sediment and associated contaminants to streams and reservoirs, potentially resulting in water that is undeliverable to cities and towns. A suitable model to determine the magnitude and likelihood of large sediment loads initiated by the random combination of fire and storm rainfall in south-eastern Australian forests does not currently exist. A new model is being developed that determines the risk of these high-magnitude sediment loads based on the combined probability of fire and storm rainfall events. The model combines deterministic models for fire spread, erosion and sediment delivery processes within an annual Monte Carlo simulation of fire ignitions and storm rainfall. By simulating fire behaviour and analysing historical fire and weather records, it is possible to estimate the probability, extent and severity of a large range of possible wildfires. This range will be combined with a range of possible storm rainfalls to give the risk of large sediment producing conditions. The Monte Carlo model is initially to be implemented in Melbourne's two largest water supply catchments, the Upper Yarra and the Thompson. These forested catchments provide Melbourne with approximately $80 \%$ of its water supply.

Current work on this model is focused on the fire modelling and this paper will deal exclusively with this part of the system. While the fire modelling method is complete, the fire model is currently in the process of calibration and validation. Fire behaviour is simulated using the PHOENIX fire behaviour model developed at the University of Melbourne. PHOENIX is presently used by Victoria's Department of Sustainability and Environment to simulate fire behaviour and model fire management scenarios. Simulated fire spread is determined by a weather time series which may also be used to calculate an instantaneous Forest Fire Danger Index (FFDI). A revised FFDI was used by PHOENIX to incorporate changes in fuel moisture in response to the variation of solar radiation over the course of the day. Wildfires were simulated using historical fire weather for the 344 worst fire days on record. These 344 days compose a partial duration series of severe fire weather days containing all daily peak FFDI days greater than the lowest annual maximum FFDI on record. These fires were individually ignited on a $6 \mathrm{~km}$ grid covering a large area of central Victoria. These simulations provided a dataset of over 80,000 possible fires to inform the Monte Carlo model.
\end{abstract}

The described approach to modelling fire behaviour will deliver the dataset required by the overall Monte Carlo model while working within the limitations of PHOENIX and the available historical weather and fire records.

Keywords: Wildfire, Fire weather, Ignition probability, Monte Carlo, Water quality 


\section{Introduction}

Wildfire is a common occurrence in south-eastern Australia, and in the last 10 years, the region has experienced some of the largest and most destructive fires ever recorded. Following these recent fires, contamination of streams and reservoirs by suspended sediment, ash and other sediment-associated contaminants (e.g. heavy metals) was observed in various locations in response to storm rainfall occurring within 1-2 years after burning (Smith et al., 2011). The importance of such fire-prone forest regions for the supply of high quality water emphasises the need to quantify the risk of water supply contamination associated with wildfire and subsequent storm rainfall events. At present, such information is not available.

The risk to Melbourne's two largest water storages, the Upper Yarra and Thompson reservoirs, forms the focus of this work. These reservoir catchment areas are heavily forested and prone to wildfire. The catchments have been directly threatened by large uncontrollable fires in 2006 and 2009, however, only a very small area of the Upper Yarra catchment was affected.

Wildfire risk to water quality cannot be determined by current available models because they do not consider the probabilistic nature of wildfire ignition, fire weather on the day of ignition, and storm rainfall. A Monte Carlo (MC) modelling approach was chosen to represent the probabilistic inputs of wildfire and storm rainfall and this will be coupled with deterministic erosion models to generate sediment loads delivered to the two reservoirs. This paper focuses on the fire modelling component of the MC model, to achieve reasonable fire ignition probabilities based on a dataset of historic fire ignitions. Model ignitions are simulated with a deterministic fire behaviour simulator and the outputs from this fire modelling will be used as inputs to hydrologic and erosion models which are not described here. This paper describes methods used to determine the probability of fire ignition on severe fire weather days, and the spatially distributed severity of the fire if ignition does occur.

\section{MODELLING APPROACH}

\section{$2.1 \quad$ Overview}

The MC simulation for the fire and water quality model runs on an annual time-step, involving the simulation of fire events and the subsequent storms that result in erosion and water quality effects. The objective of the fire modelling component is to generate annual 'burned areas' that can be used as inputs to the hydrology and erosion models. We attempt to replicate features of these burned areas most relevant to post-fire erosion processes and 'significant' water quality impacts at the catchment scale. This involves capturing the recurrence interval and size of major fires in the catchments, and the likely spatial arrangement of fire severity relative to the reservoir and the stream network.

Deterministic fire spread models offer the greatest prospect of reproducing the type of spatial and temporal detail required for erosion models. However, if we are to use such deterministic fire spread models in an annual MC type simulation, how do we determine how many fires there will be, and where they will ignite within the state? Which ones will burn forest within the catchments? Which weather observations should drive these simulated fires? To simplify this modelling problem, we introduce some assumptions. Firstly, we assume that water quality impacts will only result from 'large' fires. Secondly, we assume that 'large fires' will only occur on the 'worst' fire days in any given year (determined by an index of fire risk defined in the next section). Fires that ignite or burn on low fire risk days are assumed to make a negligible contribution to the total area burned. Finally, we delineate an area within which fires have the capacity to reach the catchments on the worst fire days; outside this area fires cannot impact on the catchments. As a result, we only simulate fires that occur on the "worst" annual fire days, within reach of the catchments of interest.

There are two distributions of severe fire weather of particular interest to this model, both taken from a historical record extending back 39 years (1971-2010). The first is a distribution of the number of severe fire weather days in each year of the historical record. The second is the distribution of the magnitude of all the severe fire weather days in the historical record. To operate the deterministic fire spread model within the annual time-step MC model, for each year, the number of severe fire weather days is randomly selected from the first distribution of annual number of severe fire weather days. On each of these severe fire weather days, the associated weather observations are sampled from the second distribution of the magnitude of severe fire weather. The probability of an ignition on this day is a function of the fire danger (described in the next section), and can be estimated from the historic fire ignition record. If a fire ignites, the ignition point is randomly located within the area where fires can reach the catchments of interest. The fire spread model then uses the fire weather observations for that day, and the spatially distributed landscape data for the region, to estimate the spatial variability of severity of the fire from this ignition point. In the rare event that two large fires ignite and burn forests within the catchments in a given year, only the fire that burns the greatest area of the catchments is considered. The 
resulting outputs will then be used as inputs for the hydrology and erosion models to calculate sediment loads. The MC model then increments another year and repeats many annual realizations of this process. A flow chart describing the annual fire modelling process within the overall MC model is shown below in Figure 1.

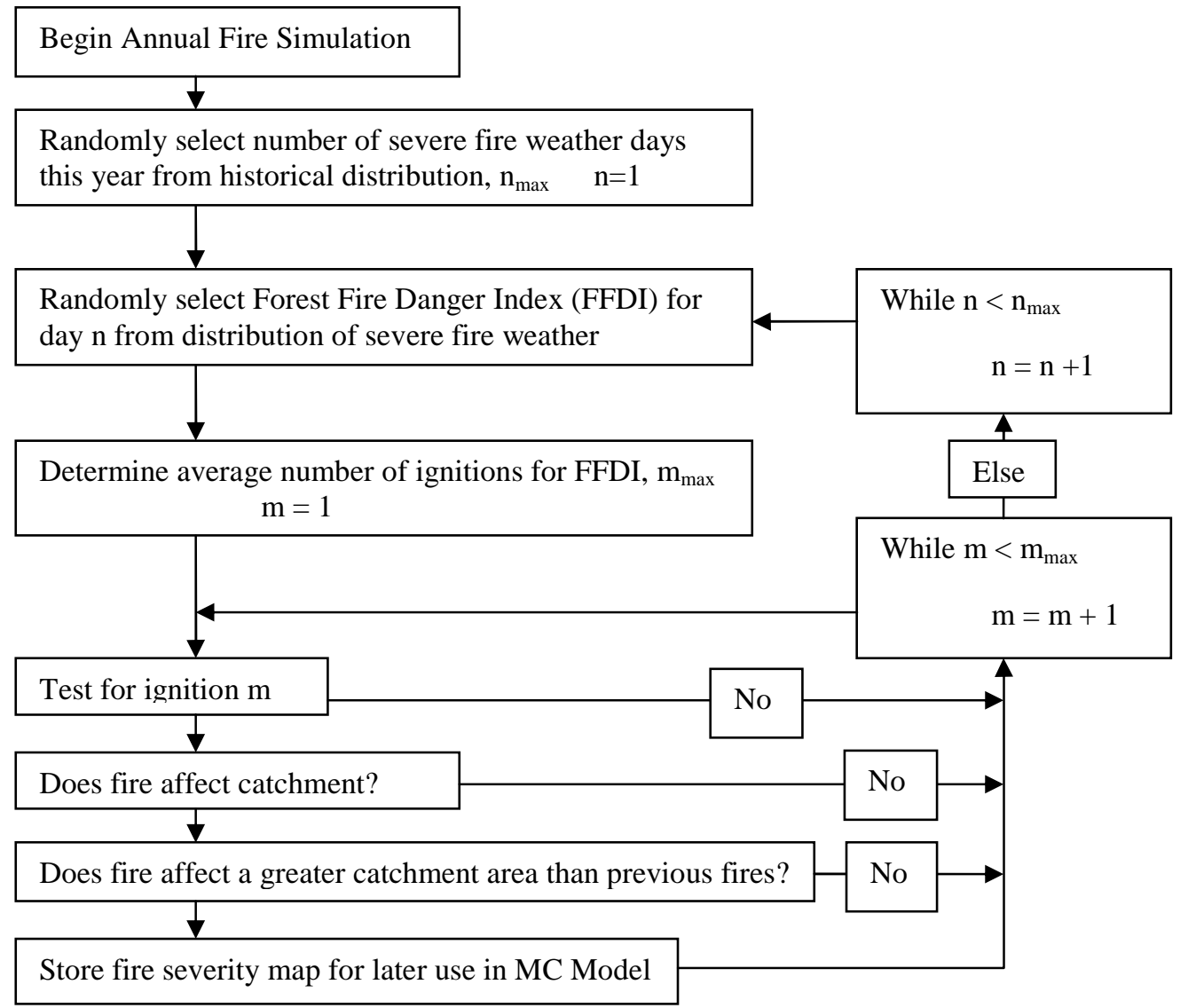

Figure 1. Flow Chart describing the fire modelling process for a single year.

\subsection{Fire Weather}

\section{Catchment composite fire weather}

To run the fire behaviour simulator, historical catchment fire weather was extracted from available data for the Melbourne Airport automatic weather station (AWS). This site was chosen because it represents the longest continuous weather dataset (temperature, wind speed, relative humidity, rainfall) measured at 30 min intervals in Victoria. The Melbourne Airport AWS record began in 1971. While alternative AWS at Dunns Hill and Kilmore Gap are closest to Melbourne Water's (MW's) catchments, their records are considerably shorter, beginning in 1991 and 1994 respectively, and so were not used. The average elevation of the two catchments is $391 \mathrm{~m}$ (Range 360m-1300m). Temperature was adjusted based on the standard Dry Adiabatic Lapse Rate (DALR) of 9.8 degrees C/1000m. Adjusted relative humidity, h, was calculated using (1) (Bolton 1980). Weather observations were used to generate a rank order of severe fire weather days.

$$
\boldsymbol{h}=\left(\frac{e s\left(t_{a}\right)}{\epsilon s(t)}\right) \times 100
$$

Where $\mathrm{e}_{\mathrm{s}}(\mathrm{x})=$ saturated vapour pressure of water with temperature, $\mathrm{x} ; \mathrm{t}_{\mathrm{d}}=$ saturated dew point temperature $\left({ }^{\circ} \mathrm{C}\right) ; \mathrm{t}=$ elevation adjusted temperature $\left({ }^{\circ} \mathrm{C}\right)$

Fire simulation requires calculation of the Forest Fire Danger Index (FFDI), however, the traditional calculation of FFDI (McArthur, 1967) considers mid afternoon peak conditions (3pm) for temperature and humidity to calculate fuel moisture. Using peak daily humidity and temperature does not consider the variability of solar radiation over the day and the subsequent variation in fuel moisture. Using McArthur's equation for fuel moisture (2) would therefore overestimate fire spread potential by not considering reduced solar radiation earlier and later in the day. 
An alternative FFDI calculation (Mathews, 2009) based on fine fuel moisture was subsequently used to capture the effect of solar radiation in the fuel drying process. Fuel moisture was calculated using a simplified single layer process model (3) derived by Matthews from his more complex model (Matthews, 2006). This allowed a diurnal FFDI to be calculated for each day's weather observations. Matthews' function for fuel moisture was substituted for McArthur's function in the FFDI calculations used by the fire behaviour simulator.

$$
\text { Matthews' } f(m)=27,3 m^{-8,1}
$$

Where $\mathrm{m}=$ fuel moisture $(\%)$

This calculation of fuel moisture was then incorporated into Matthews' FFDI equation (4).

$$
F F D I=1.275 \text { e(a)f(m)g(w) }
$$

Where $\mathrm{a}=$ fuel availability index $(0-1), \mathrm{w}=$ wind speed $(\mathrm{km} \mathrm{h}-1)$

\section{Partial duration series for severe fire weather days}

A partial duration series (PDS) of 344 severe fire weather days was created from the 39 year historical weather record of Matthews's peak daily FFDI (FFDI ${ }_{\max }$ ). PDS have been used extensively to analyse extreme events in hydrology (Langbein, 1949; Kirby \& Moss, 1987). The annual maximum FFDI max $_{\text {was }}$ walculated for each year of the weather record. The lowest of these was used as the PDS threshold and all days with an FFDI max ${ }_{\text {above }}$ this threshold were included in the PDS. The lowest calculated FFDI max $_{\text {was }} 23$ and occurred in 1971 and 1974.

\subsection{Historical ignition probability}

\section{Historical large fire ignition}

To determine the average number of ignitions in the historical record on the severe fire weather days, the PDS was grouped into $\mathrm{FFDI}_{\max }$ categories (Figure 2).

The average number of historical ignitions for each $\mathrm{FFDI}_{\max }$ category varies depending on the size of fires that are considered in the record. Since the record includes many thousands of small fires which are assumed to be of negligible risk to water quality, using all the historical fires to determine ignition probability will unrealistically raise the chance of a large fire being modelled. For

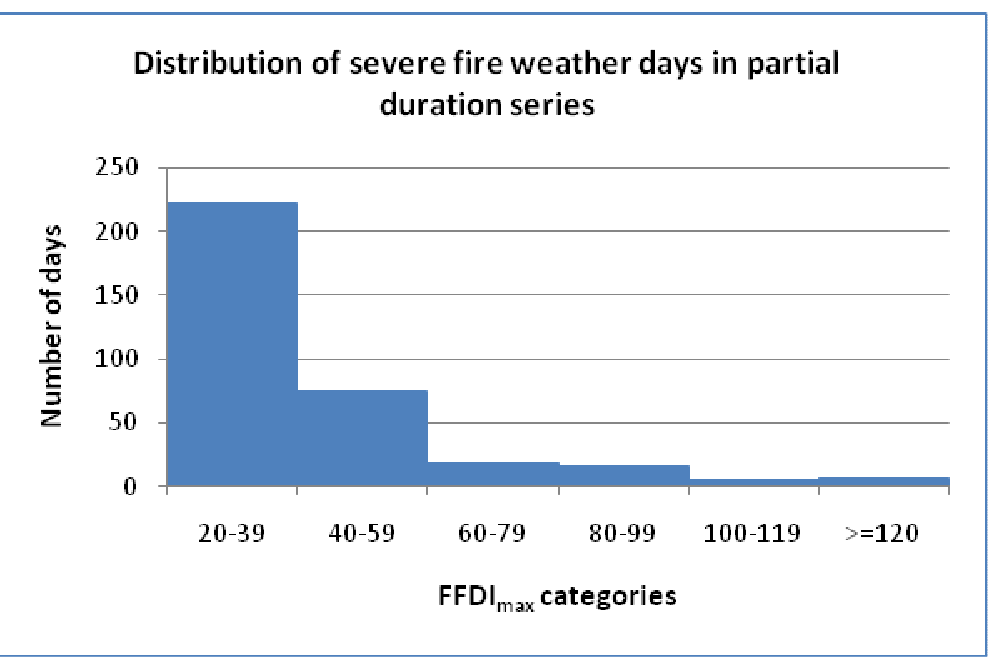
example, when considering all fires in the historical record greater than 1 ha, the average number of fires that ignite each day is very large. Since we are most interested in large uncontrolled fires that may affect water quality, a historical 'fire size

Figure 2. FFDI $_{\max }$ categories of partial duration series of severe fire weather days

cut-off' is used as a calibration parameter so that it is possible to match the number of model ignitions with the number of fires in the record. Table 1 describes the variation in average ignitions for each FFDI $\max _{\operatorname{mat}}$ catery as this calibration parameter is adjusted. 
Table 1. Variation in average number of daily fire's when increasing the size of fires considered in the historical record (i.e. increasing the cut off calibration parameter)

\begin{tabular}{|l|r|r|r|r|}
\hline FFDI & $\begin{array}{r}\text { Average number } \\
\text { of fires per day } \\
\text { when considering } \\
\text { only fires > 1 ha }\end{array}$ & $\begin{array}{r}\text { Average number } \\
\text { of fires per day } \\
\text { when considering } \\
\text { only fires > 10 ha }\end{array}$ & $\begin{array}{r}\text { Average number } \\
\text { of fires per day } \\
\text { when considering } \\
\text { only fires > 50 ha }\end{array}$ & $\begin{array}{r}\text { Average number } \\
\text { of fires per day } \\
\text { when considering } \\
\text { only fires > 100 ha }\end{array}$ \\
\hline $20-39$ & 2.3 & 0.8 & 0.4 & 0.3 \\
$40-59$ & 1.5 & 0.6 & 0.4 & 0.3 \\
$60-79$ & 1.9 & 0.9 & 0.4 & 0.4 \\
$80-99$ & 2.1 & 0.8 & 0.4 & 0.4 \\
$100-119$ & 3.4 & 1.6 & 0.8 & 0.6 \\
$>=120$ & 10.7 & 6.3 & 4.3 & 3.4 \\
\hline
\end{tabular}

\section{Catchment Fire Danger Zone}

The 'catchment fire danger zone' (CFDZ) is the area surrounding the Upper Yarra and Thompson catchments within which a fire ignition may threaten the catchments. The size of this area was determined by using 'Black Saturday' (7 February 2009) fire weather conditions and considering the longest fire run distances possible in 24 hours. Preexisting fires that enter the CFDZ are represented by ignition at a boundary point. The CFDZ for these two catchments is defined by the 239 igntion points in Figure 3.

These ignition points form part of a $6 \mathrm{~km}$ grid of ignition points which was used by the fire behaviour simulator to determine the extent of the CFDZ. Ignition was restricted to this resolution so that a finite number of fires could be pre-processed by the fire simulator as a batch and the outputs stored. These fires form a particular scenario of fire weather and fuel loads that can then be accessed by the MC model.

Catastrophic wildfire events such as occurred on 'Black Saturday' (2009) and 'Ash Wednesday' (1983) are particularly devastating due to strong NW winds associated with the severe fire weather which creates a long thin fire, followed by a cooler SW wind change. The wind change converted the flank of the fire into an extremely long fire front (Figures $4 \mathrm{a}$ and $4 \mathrm{~b}$ ), resulting in a fire with a very

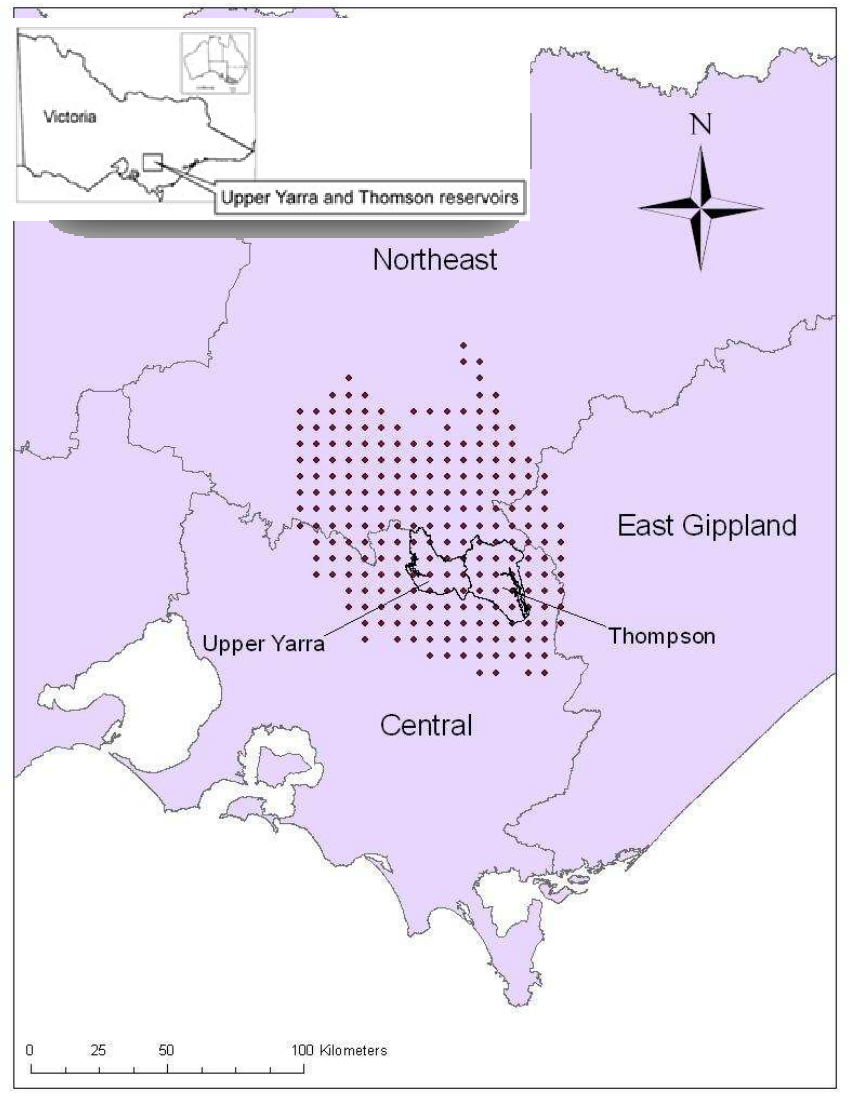

Figure 3. Catchment fire danger zone showing PHOENIX ignition points and Victoria's 'fire areas' large burn area.

\section{Ignition probability within the CFDZ}

To determine the ignition probability within the CFDZ, we considered a historical fire record area with similar weather, forest type and elevation. This area may be limited to specific forest types and elevations, however, this will reduce the size of the historical fire dataset. For the purposes of this initial analysis we consider historical fires that occur within three of Victoria's five 'fire areas'. These areas approximate the terrain of the catchment danger zone and are the Central, Northeast and East Gippsland fire areas (Figure 3).

The average number of historical ignitions for the severe fire weather days in each category will determine the probability that a fire will ignite on the severe fire weather day being modelled. The probability of each of these historical ignitions occurring within the CFDZ is proportional to the area difference between the CFDZ and the area considered in the historical fire record. Since the CFDZ has $7 \%$ the area of the three fire areas, for each ignition in the record, we assume that there is a $7 \%$ chance that an ignition occurs at a random location in the CFDZ. If the number of average ignitions is less than 1 then the ignition probability of $7 \%$ is multiplied by the 
fraction. If the average number of ignitions is more than 1, an ignition test is made separately for each of the possible ignitions.

For example, if a given day has an $\mathrm{FFDI}_{\max }$ of 130 and a fire size cut-off of 50 ha is used, then the average number of ignitions on this day will be 4.3 (from Table 1). The model will make 5 ignition tests; 4 tests for ignition with a $7 \%$ probability and 1 test at $(0.3 \times 7 \%) 2.1 \%$ probability.

If an ignition does occur in the CFDZ, the ignition location is randomly selected from the 239 gridded ignition points (Figure 3).

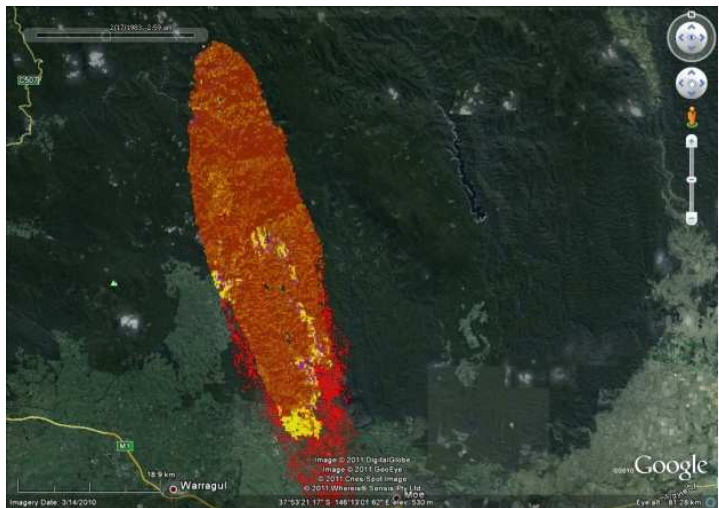

Figure 4a. Ash Wednesday fire simulation, 5 hours after ignition, wind from NW

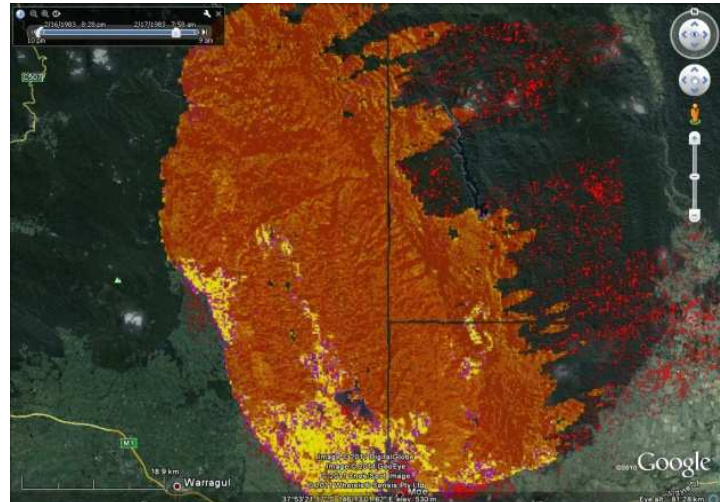

Figure 4b. Ash Wednesday fire simulation, 10 hours after ignition, wind has changed to the SW

\subsection{PHOENIX fire modelling}

PHOENIX is a dynamic fire behaviour and characterisation model developed at The University of Melbourne (Tolhurst et al., 2008). PHOENIX considers changes in fuel, weather and topographic conditions of the fire as the fire grows and moves across the landscape. Fire behaviour models estimate the point rate of spread, flame height and fire intensity. A fire spread algorithm determines the fire behaviour at each point around the fire perimeter. PHOENIX also incorporates a number of other models dealing with ember transport and distribution, spot-fire ignition, wind-slope interactions, linear disruption to fire behaviour, fuel accumulation rates, solar radiation and fuel moisture models. PHOENIX is grid-based; the cell resolution of these fire simulations was $200 \mathrm{~m}$.

There are a number of outputs of interest to fire modellers, including flame height and fire intensity. We use these values to determine the effect of the fire on the soil and vegetation to permit modeling of post-fire erosion. Each of the 344 severe fire weather days was simulated separately with PHOENIX at all 239 ignition points within the CFDZ (Figure 2). This results in a total of 82,216 spatially distributed fire maps, each unique to a particular severe fire weather day and ignition point. Figure 5 displays a medium size fire of approximately 20,000 ha, simulated under weather conditions with an $\mathrm{FFDI}_{\max }$ of 50.

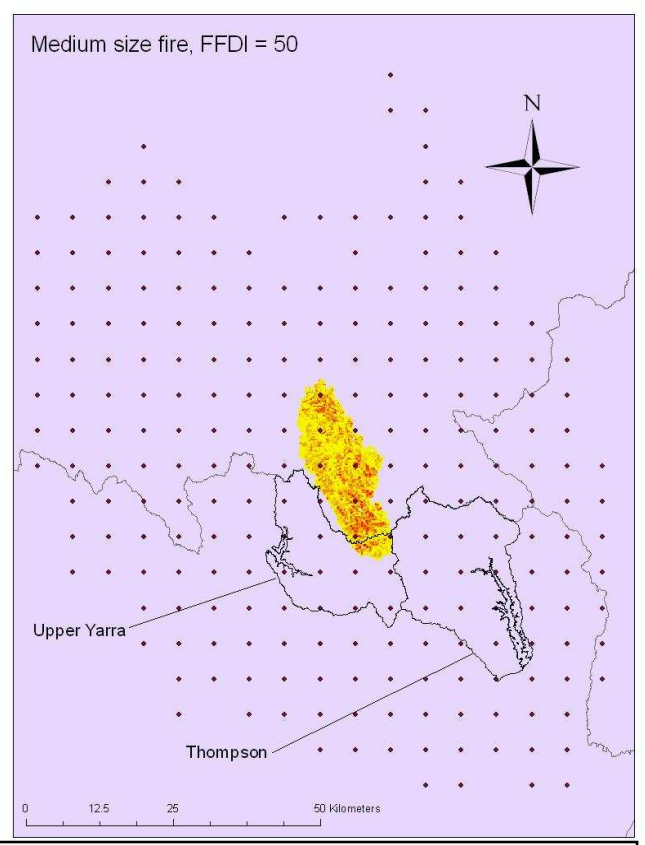

Figure 5. Medium size fire, FFDI $=50$ Figure 6 displays a fire simulated using Black Saturday weather conditions. The FFDI ${ }_{\max }$ on this day was 149 . In these examples, the colour of the fire cells represents relative intensity, increasing from yellow to red.

\section{EVALUATION OF FIRE MODELLING APPROACH}

There are a number of advantages to performing the fire modelling in the method described above. Since PHOENIX models all the severe fire weather days in a batch as a scenario and the MC model selects from these fires, additional scenarios where different spatial fuel loads and suppression techniques are applied may be modelled by PHOENIX and easily replaced in the MC model. This allows assessment of the effect of different scenarios (such as prescribed burning) on suspended sediment loads. Another advantage is that the spatial arrangement of fire severity is considered. Recent research by Moody (et al., 2008) and Robichaud (et al., 2007) 
shows that the spatial arrangement of fire severity is an important feature in the production of sediment from burnt hillslopes.

There are also disadvantages associated with this fire modelling approach. PHOENIX only simulates fires for a maximum 24 hour period, so large fires which burn for many days are not simulated. This is consistent with the view that the majority of a major wildfire's burnt area occurs on one severe fire day. This approach does not consider multiple fires which may ignite on the same day or the interaction of multiple fires in one year. This is a constraint of this modelling approach because PHOENIX is used to preprocess fire simulations so the change in spatial fuel load of a fire burning an area already burnt cannot be considered. This disadvantage may be minimised due to the rarity of extreme fire events. This overall approach is believed to be acceptable because the number of large fires is relatively low, and these fires are uncommon within the relatively small area of the CFDZ.

\section{FUTURE WORK}

To complete this fire modelling approach, calibration will take place

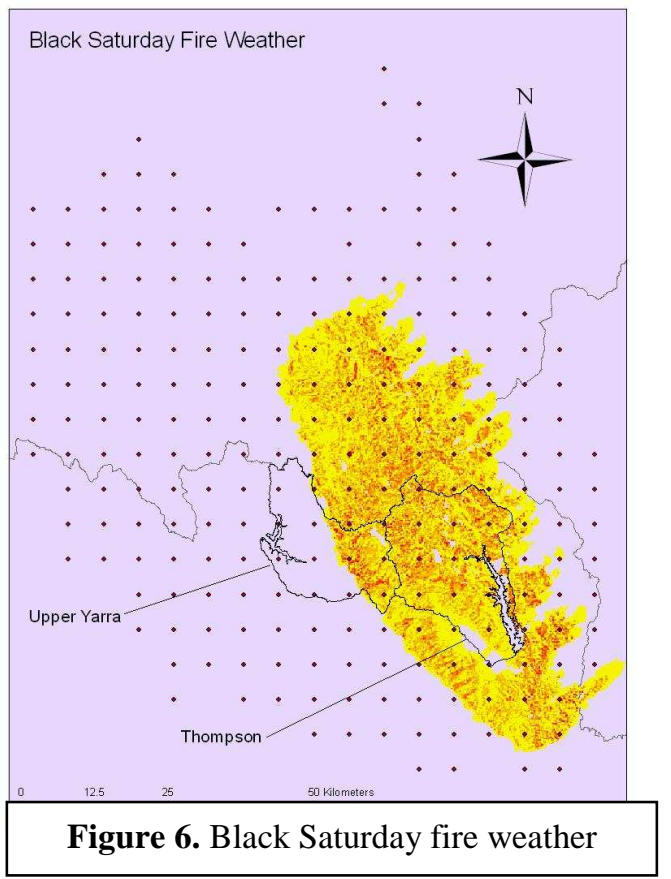

to determine the 'cut-off' fire size (described earlier) most appropriate, such that the number of modelled fires is consistent with the historic record. Preliminary testing puts this cut-off value between 10 and 50 ha. The intensity and flame height in each fire map cell will be converted into a soil burn severity (Shakesby \& Doerr, 2006). This severity can be related to soil properties which parameterise erosion models. Maximum annual rainfall or storms with known recurrence intervals will then drive erosion models so that the range of postwildfire sediment loads may be estimated.

The effect on water quality of a range of fire scenarios may be compared in the future. A range of prescribed fire burns may be simulated by changing input fuel loads. A range of suppression methods may be compared as these options are already available within PHOENIX. Climate change effects may be compared by altering weather inputs. The overall MC model has been designed so that these scenarios can be compared easily.

\section{ACKNOWLEDGMENTS}

This research is funded by Melbourne Water as part of the 'Wildfire and Water Security Research Program'.

\section{REFERENCES}

Bolton, D. (1980). The computation of equivalent potential temperature. Monthly Weather Review 108(7): 1046-1053.

Kirby, W., Moss, M. (1987). Summary of flood-frequency analysis in the United States. Journal of Hydrology 96(1-4): 5-14.

Langbein, W.B. (1949). Annual floods and the partial-duration flood series. Trans. Am. Geophys. Union, 306 , pp. 879-881.

McArthur, A. (1967). Fire behaviour in eucalypt forests. Forestry and Timber Bureau, Canberra.

Matthews S. (2006). A process-based model of fine fuel moisture. International Journal of Wildland Fire 15,155-168.

Matthews, S. (2009). A comparison of fire danger rating systems for use in forests. Australian Meteorological and Oceanographic Journal 58, 41-48.

Moody, J., Martin, D., Haire, S., Kinner, D. (2008). Linking runoff response to burn severity after a wildfire. Hydrological Processes 22(13): 2063-2074.

Robichaud, P., Elliot, W., Pierson, F., Hall, D., Moffet, C. (2007). Predicting postfire erosion and mitigation effectiveness with a web-based probabilistic erosion model. Catena 71(2): 229-241.

Shakesby, R., Doerr, S., (2006). Wildfire as a hydrological and geomorphological agent. Earth-Science Reviews 74(3-4): 269-307.

Smith, H.G., Sheridan, G.J., Lane, P.N.J., Nyman, P., Haydon, S. (2011). Wildfire effects on water quality in forest catchments: a review with implications for water supply. Journal of Hydrology, 396: 170-192.

Tolhurst, K., Shields, Chong, D. (2008). Phoenix: development and application of a bushfire risk management tool. The Australian Journal of Emergency Management, Vol. 23 No. 4, November. 